ISSN: 2637-4676

\title{
Fast Food Pork in North America
}

\section{W Jon Meadus*}

Agriculture and Agri-Food Canada, AAFC-Lacombe, Canada

Received: 嘴 May 02, 2018; Published: 㘹 May 14, 2018

*Corresponding author: W Jon Meadus, Agriculture and Agri-Food Canada, AAFC-Lacombe, Canada

\section{Introduction}

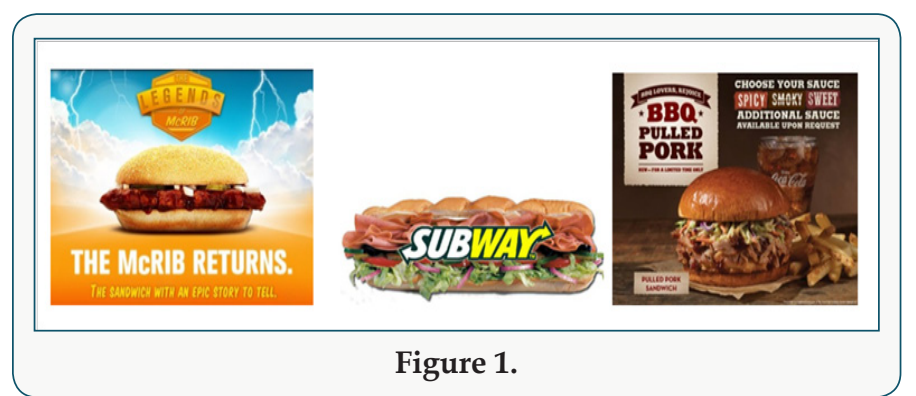

Try to remember the last time you bought a pork item at a fast food restaurant in North America. Not a ham sandwich from Subway or a breakfast sandwich from Tim Hortons but a pork burger from MacDonald's, Wendy's, A\&W, or Burger King. They have tried in the past offering the McRib from McDonalds but the closest permanent pork menu item, is an offer of bacon to act as a flavor accent but no real pork burgers. Now in 2018, we have the pulled pork sandwich which comes lathered in BBQ sauce, which actually might make a lasting impression but is it really a pork product or a sauce product? (Figure 1). Pork vs Beef Burger, What's the Difference FAT. Ground pork is relatively cheap when compared to beef burgers, sometimes almost half the price of regular ground hamburger (beef burger) but pork burgers have not made much progress into the fast menu in North America. Maybe it is the amount or type of fat? In Japan, they describe a pork and beef burger mixture as 'aibiki niku'. The mixture can reach 50/50 and the flavour is described as being 'un-detectable' from standard $100 \%$ beef burger. If it is $100 \%$ beef, then it is often labelled as ' $100 \%$ Wagyu' beef burger. Fat is assumed to be the main influence on flavour and beef has much less polyunsaturated fat (PUFA) than pork. Beef products typically have $15 \%$ more saturated fat (SFA), $7 \%$ less monounsaturated fat (MUFA) and 8\% less polyunsaturated fat (PUFA) than pork [1] because Beef cattle naturally convert much of the MUFA and PUFA in their feed to SFA, by bacteria in the rumen. The USDA list the typical $28 \mathrm{~g}$ beef burger of having $0.4 \mathrm{~g}$ of PUFA and $6.2 \mathrm{~g}$ of SFA. Pigs, being monogastrics, do not have this conversion ability in their gut, so the composition of their fat mainly reflects the type of fats in their diet.
An attempt to get the lipid profile in pork to mirror the profile of beef has been tried. The premise is that by feeding pigs a diet high in SFA fat (eg. beef tallow), pigs would have a more beefy flavour but the experimental evidence shows that when feeding pigs either, beef tallow, coconut oil, or palm oil, which all have a much higher SFA content than normal pigfeed, the PUFA to SFA ratio stays relatively the same in the pork [2]. For instance, feeding $5 \%$ coconut oil increased the SFA content $\sim 3 \%$ [3] but the fat in a typical 28g ground pork burger is still $\sim 1.6 \mathrm{~g}$ of PUFA and $6.6 \mathrm{~g}$ of SFA, which is $4 \mathrm{X}$ the amount of PUFA in a beef burger, according to USDA nutrition data (http:// nutritiondata.self.com) TASTE and ODOUR. The PUFA and MUFA fats are generally considered as being healthier than SFA, unless it is trans-fat. The MUFA oleic acid (C18:1) is an 18 carbon molecule with one cis unsaturated bond at the 9 position and is the most common MUFA beef fat. It brings a pleasant taste to meat and is also found in olive oil. Of the PUFAs, linoleic acid (C18:2 omega-6) and linolenic acid (C18:3 omega-3) are essential to the human diet and a balance of the two are needed for health. Pork fat naturally has a greater amount of PUFA than beef, and the proportion in the fat can be altered more easily than in cattle, making it easier to market a burger that matches the dietary requirements and can be marketed as 'healthy'.

Pork may have a better healthy MUFA and PUFA content than beef but PUFAs also have a greater susceptibility to oxidation due the presence of double bonds which can be complexed with oxygen. Oxidation leads to undesirable warmed-over-flavours (WOF) and rancidity [4]. The SFA to PUFA ratio is about the same in sheep as beef but meat from older sheep also has a distinct undesirable odour or taste described as 'mutton'. Mutton PUFAs have a combination of unique branch chain fatty acids and phenols and lanolin and iso-stearic acid Wong et al. 1975. Poultry PUFAs are particularly susceptible to WOF which is due to a combination of oxidized fatty acids and sulfur compounds, dimethyl sulfoxide. There are other undesirable smells and flavours associated with pork and beef beside WOF. Pork from intact male pigs can have an odor called 'boar taint' which is a combination of a steroid 'androst-16-enone' 
which is formed in the testis and skatole which is metabolized from the bacteria mainly present in the hindgut of pigs. Beef, on the other hand, can have liver flavours which occur with high myoglobin content and extra PUFA content. In 1986, the identifiable volatile beef aromatic components counts reached over 600 [5]. However, the influence of these components is undetectable by consumers, unless they are significantly concentrated by poor raising, age or storage conditions.

\section{Colour}

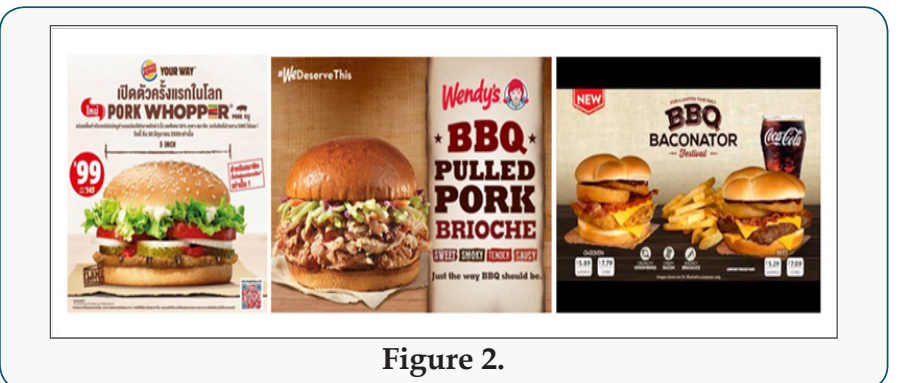

There is a redder colour in the beef burger but this is diluted out as you go from extra-lean ground meat to the fatter ground meat used in a regular burger. The amount of red is caused mainly by the myoglobin. In pork, myoglobin is much lower at $2 \mathrm{mg} / \mathrm{g}$ versus $8 \mathrm{mg} / \mathrm{g}$ to $12 \mathrm{mg} / \mathrm{g}$ for beef. This led pork advertiser in the $1980 \mathrm{~s}$ and 90 s to try the slogan 'pork, the other white meat' for many years. In contrast, a bison hamburger has very high myoglobin content at $\sim 15 \mathrm{mg} / \mathrm{g}$ but this can give purple colour and early discolouration/browning on air exposure. A direct comparison of myoglobin between beef and bison show very little difference in the sequence and even tuna $(5 \mathrm{mg} / \mathrm{g}$ ) has essentially the same basic myoglobin sequence Levy 1985. The higher myoglobin content has also been associated with liver flavours [6]. Protecting the color is maintained by a using modified gas packaging like carbon monoxide and treating it with alpha-tocopherol (vitamin E). Vitamin E also helps to prevent WOF and oxidations of unsaturated fats COST. A big factor consumer's use in deciding the choice of beef verses pork is price (Figure 2). Traditionally in North America, there may be a preference for the beef burger over the pork burger because of the expected value difference. Beef steaks costs are much higher than pork chops, almost double the price [6]. In 2017, the cost of ground beef was between $\$ 5$ and $\$ 6$ dollar a pound and pork was approximately at less than $\$ 4 / \mathrm{lbs}$.

\section{Conclusion}

The bottom line is consumer acceptance. With the recent trend of hormone- and antibiotic-free label on the fast food burger gaining popularity, the cost of raising the meat will have to be absorbed by the fast food chain. More pressure on the fast food companies will results in renewed efforts to try and market ground pork burger products. In places like China and Indonesia, it has already met some success. Today (2018) in North America there is a demand for adding a pork bacon condiment on the standard beef burger for flavour. Pork bellies, from which bacon is made, are enjoying such a premium price that they are competing with pork loins, on a price per pound basis. The fast food industry may have to reformulate for a leaner pork burger to compensate for the bacon in the toppings, and for the extra $2 \mathrm{~g}$ of fat in a typical $28 \mathrm{~g}$ pork burger over the traditional beef burger.

\section{References}

1. Campo MM, Nute GR, Wood JD, Elmore SJ, Mottram DS, et al. (2003) Modelling the effect of fatty acids in odour development of cooked meat in vitro: Part I - Sensory perception. Meat Science 63(3): 367-375.

2. Vasta V, Priolo A (2006) Ruminant fat volatiles as affected by diet. A review. Meat Sci 73(2): 218-228.

3. Park JC, Kim SC, Lee SD, Jang HC, Kim NK, et al. (2012) Effects of dietary fat types on growth performance, pork quality, and gene expression in growing-finishing pigs. Asian Australasian Journal of Animal Sciences 25(12): 1759-1767.

4. Jensen C, Flensted Jensen M, Skibsted LH, Bertelsen G (1998) Warmedover flavour in chill-stored pre-cooked pork patties in relation to dietary rapeseed oil and vitamin E supplementation. Zeitschrift fur Lebensmittel Untersuchung und Forschung A, Food Research and Technology 207(2): 154-159.

5. Shahidi F, Rubin LJ, D’Souza LA (1986) Meat flavor volatiles: a review of the composition, techniques of analysis, and sensory evaluation. Crit Rev Food Sci Nutr 24(2): 141-243.

6. Joseph P, Suman SP, Li S, Beach CM, Steinke L, et al. (2010) Characterization of bison (Bison bison) myoglobin. Meat Sci 84(1): 71-78.
(C) (P) This work is licensed under Creative

To Submit Your Article Click Here: Submit Article

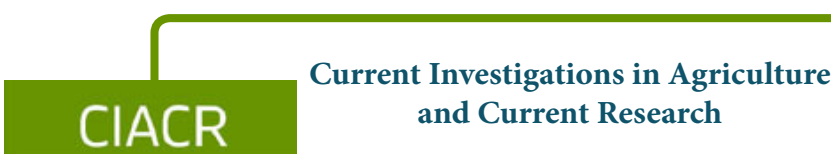

Assets of Publishing with us

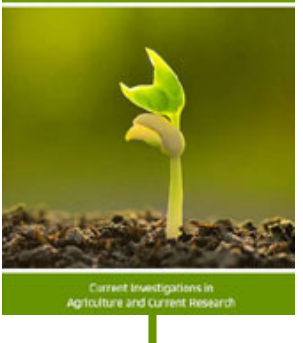

- Global archiving of articles

- Immediate, unrestricted online access

- Rigorous Peer Review Process

- Authors Retain Copyrights

- Unique DOI for all articles 